\title{
Minerals security of supply: a geological perspective
}

\author{
A G Gunn and A J Bloodworth \\ British Geological Survey, Keyworth, Nottingham, NG12 5GG, UK.
}

\begin{abstract}
Numerous authors, going back more than 200 years, have expressed concern about the adequacy of natural resources to support economic growth and the spread of prosperity. Most of these predictions are unnecessarily alarmist and are based on over-simplistic analysis of mineral reserve and consumption data. In fact, despite rapidly increasing demand, continued scientific and technological innovation have ensured that economic development has never been constrained by lack of mineral resources. However, 'critical metals,' so called because of their growing importance in new and green technologies and the high risk of supply shortage, present a particular problem because our knowledge of them is limited and many are by-products of major industrial metals. There is now an urgent need for research on all aspects of the life cycles of these metals to ensure their future availability.
\end{abstract}

\section{Introduction}

Global concerns are growing over the long-term availability of secure and adequate supplies of the minerals and metals needed by society. Consumption of most metals has increased steadily since World War II and demand is expected to continue to grow in response to the burgeoning global population, economic growth (especially in developing countries) and the requirements of new technologies, particularly those needed to support the development of low carbon economies. The supply of minerals depends on their physical availability in the Earth's crust and on accessing the deposits in which they occur. Access depends on numerous social, cultural, geopolitical, environmental and economic factors, which, together or singly, can determine whether the flow of minerals continues without disruption. This article focuses on the availability of metals and highlights some priorities for research to ensure that economic development is not constrained by metal scarcity.

\section{Scarcity and scare stories}

There has long been concern over the adequacy of natural resources to support economic growth and the spread of prosperity. In 1798 Thomas Malthus expressed apocalyptic views that the physical limits of some metal and mineral resources were approaching and similar 'scare stories' predicting metal scarcity and exhaustion of stocks continue to appear today (Cohen, 2007; Ragnarsdóttir, 2008). Such predictions can have serious consequences because they may lead to price volatility which discourages investment in mineral exploration and development. They may also influence government policy and research directions and thus impact on the development of new technology.

However, these forecasts are commonly based on an over-simplistic view of the relationship between reserves and consumption (i.e. number of years supply remaining equals reserves divided by annual consumption). Metal stocks of which we know the precise location, tonnage and which we can extract economically with existing technology (known as 'reserves') are tiny in comparison to the total amount present in the Earth's crust and which potentially may be exploited in the future. Published reserve figures are neither fixed nor well known and hence are not reliable indicators of the future availability of metals. In 1970 global copper reserves were estimated to be 280 million tonnes, but by 2010 this had risen to 630 million tonnes despite copper consumption in the intervening 40-year period of 400 million tonnes. Clearly consumption and reserves change continually in response to market forces and scientific advances. If metal prices rise then the size of the reserve will increase as lower grade ores become economic, while if prices fall, only higher grade material remains economic to extract and the reserve level shrinks. In fact, for many decades scientific and technological innovation have allowed us to replenish reserves from new discoveries, and to process lower grade and different types of ores (Figure 1). A number of classes of mineral deposits that were virtually unknown 50 years ago now make major contributions to the global supply of several metals. Prominent examples include porphyry deposits, which are the world's principal sources of copper, molybdenum and rhenium, and unconformity-related uranium deposits which host the largest share of global uranium resources. 

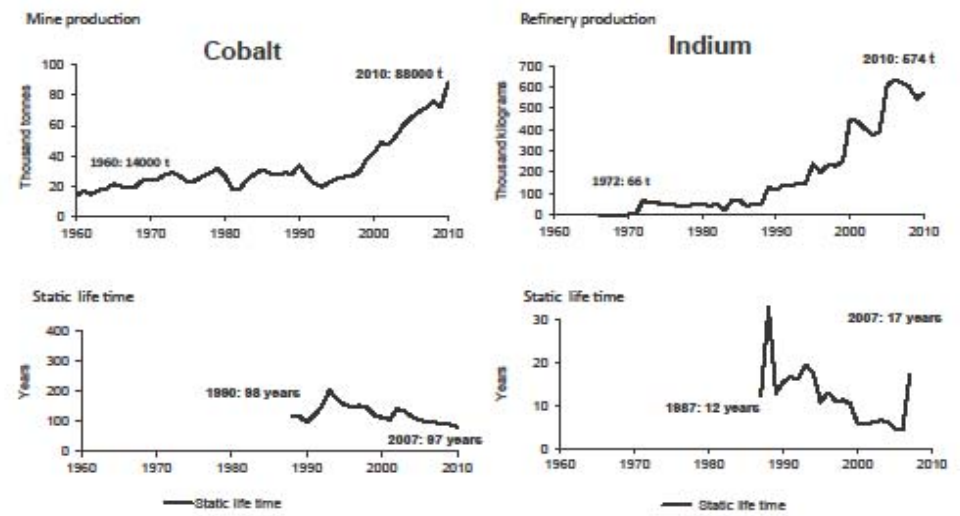

Figure 1: Despite escalating global production, reserves of metals have been continually replenished. These graphs show that static life times (number of years supply remaining equals reserves divided by annual consumption), in this case of cobalt and indium, are extended ahead of production.

(High res version of figure supplied as eps file)

\section{Critical metals}

Of particular concern are the 'critical metals', so called because of their growing economic importance and high risk of supply shortage. The production of these metals is concentrated in a few countries, most notably China, and the UK and the EU are almost wholly dependent on imported supplies. The supply risk is compounded by their low substitutability and recycling rates, which are commonly less than 1\% (UNEP, 2011). The critical metals are also characterised by certain other features which make them less attractive to investment. In particular, the markets for most critical metals are very small: for example, in 2010 the estimated global production of rare earth oxides was 122,000 tonnes, of beryllium 400 tonnes, and germanium 120 tonnes. These are dwarfed by the production of the major industrial metals, such as iron ore (2.6 billion tonnes), bauxite (219 million tonnes) and copper (16.2 million tonnes) (British Geological Survey, 2012).

Another important factor in the supply of many rare metals is that they are obtained almost entirely as byproducts of the mining of major industrial metals. For example, there are currently no tellurium or indium mines anywhere in the world, with nearly all tellurium a by-product of copper refining and nearly all indium of zinc refining. Unlike the major metals which have large markets with many suppliers, where a significant increase in demand would lead to a market-driven increase in supply, no producer of a major metal is likely to increase the production of the main metal simply to produce more of a by-product. It is therefore difficult to predict the capacity of the supply chain to meet increased demand for the by-product. For example, in the event of rapid growth in demand for tellurium in cadmium-telluride photovoltaic cells, existing supplies from copper refineries would not be adequate and research would be required to increase tellurium recovery from copper ores and to investigate other types of ore, possibly associated with gold, or even primary tellurium deposits capable of supporting 'stand alone' production. For some other metals, for example indium, the outlook is clearer. The indium market, chiefly for use in flat panel displays in televisions and portable electronic devices, has grown rapidly in recent years, with global production doubling since 2000 . This growth looks set to continue, especially if indium use in thin film photovoltaic cells is widely adopted. Currently only $25-30 \%$ of indium that is extracted from the ground in zinc ores is actually recovered and delivered as refined indium (Indium Corporation, 2012). The rest ends up in waste streams. There is little doubt that indium 
production can be increased, by working ores that are richer in indium, by installing new indium extraction plants at the base metal smelters, by improving the recovery efficiency at existing indium plants and by increased recycling.

\begin{tabular}{|l|l|l|l|l|l|l|}
\hline \multicolumn{1}{|c|}{ Copper } & \multicolumn{1}{c|}{ Zinc } & \multicolumn{1}{c|}{ Tin } & \multicolumn{1}{c|}{ Nickel } & Platinum & Aluminium & \multicolumn{1}{c|}{ Iron } \\
\hline Cobalt & Indium & Niobium & Cobalt & Rhodium & Gallium & REE \\
\hline Molybdenum & Germanium & Tantalum & PGM & Ruthenium & & Niobium \\
\hline Rhenium & & & & Osmium & & \\
\hline Tellurium & & & & iridium & & \\
\hline Selenium & & & & & & \\
\hline
\end{tabular}

Table 1: By-product metals derived from the production of selected major industrial metals (top row, bold). Those metals shown in italics are also produced from their own ores. (PGM, platinum-group metals; REE, rare earth elements).

\section{A strategy to ensure availability and sustainability}

Although physical exhaustion of primary metal resources is unlikely, there are no grounds for complacency. Unlike the major industrial and precious metals, such as iron, copper and gold, only in the last two decades have widespread applications for metals such as the rare earth elements (REE), indium, tantalum, lithium, germanium, rhenium and niobium become important. Consequently little attention has been paid to these increasingly critical metals. To ensure their future availability there is now an urgent need for research on all aspects of the life cycles of these metals, from exploration, mining and processing of ores, to manufacturing, recycling and ultimately disposal.

Improved understanding of the processes responsible for the mobilisation, transport and concentration of the critical metals in the Earth's crust will allow us to identify new exploration targets and to develop new technologies for the detection of buried deposits, especially those types enriched in these metals. There is also a need to carry out more exploration, both in terranes where we have not looked before or which were previously targeted only for gold or base metals. It will be particularly important to evaluate the mineral potential of 'new frontiers' such as the ocean floors and the polar regions. We will also need to investigate deeper geological targets than is currently the norm. The average thickness of the Earth's crust is about 35 kilometres and yet, at present, most exploration drilling outside established mining districts does not exceed 200 metres in depth (European Commission, 2010).

We will need to study the environmental costs of mineral resource extraction, processing and use. Only major research and innovation can break the current link between metal use and greenhouse gas emissions. Of particular importance will be the development of low-carbon extraction technology such as in-situ mining of uranium and microbial bio-leaching of copper, nickel and zinc from extracted ores. Such methods will significantly extend the resource base by allowing sustainable working of previously uneconomic ore types and grades.

\section{Conclusions}

Predictions of metal scarcity and depletion are generally based on a flawed understanding of mineral reserve and consumption data. Geological scarcity has not been a problem in the past because industry has responded to increasing prices by raising output. This new demand led to technological innovation and the identification of new resources. The requirements of new technologies, particularly those needed for lowcarbon economies, will require increasing quantities of certain critical metals which have been little used in the past and many of which are by-products of the major industrial metals. However, given adequate and timely investment in research into all parts of the critical metals life cycle, physical scarcity of supply is considered unlikely.

\section{References}

British Geological Survey. (2012) World Mineral Production 2006-10 (Keyworth, Nottingham: British Geological Survey). 
Cohen, D. (2007) Earth's natural wealth: an audit. New Scientist, 23 May 2007, 34-41.

European Commission. (2010) Critical Raw Materials for the EU. Report of the ad-hoc working group on defining critical raw materials. http://ec.europa.eu/enterprise/policies/raw-materials/critical/index_en.htm

Indium Corporation. (2012) Indium Sources and Applications. Presentation by Malcolm Harrower, Minor Metals Conference, February 2012.

Ragnarsdóttir, K.V. (2008) Rare metals getting rarer. Nature Geoscience 1, 720-721.

UNEP (United Nations Environment Programme). (2011) Metal recycling rates: a status report. http://www.unep.org/resourcepanel/Portals/24102/PDFs/Metals_Recycling_Rates_110412-1.pdf. 
Mine production

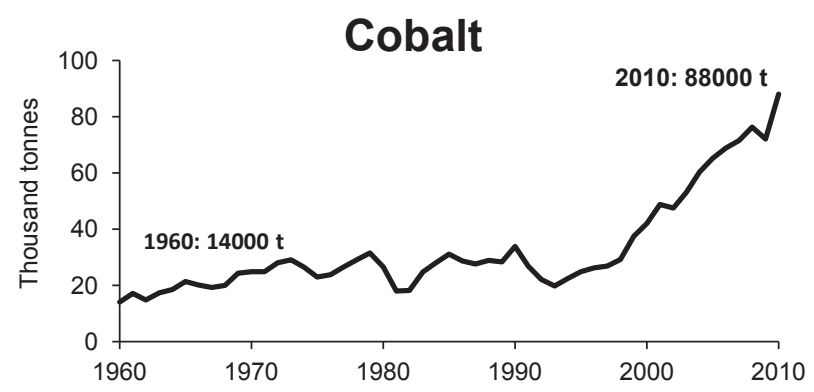

Static life time

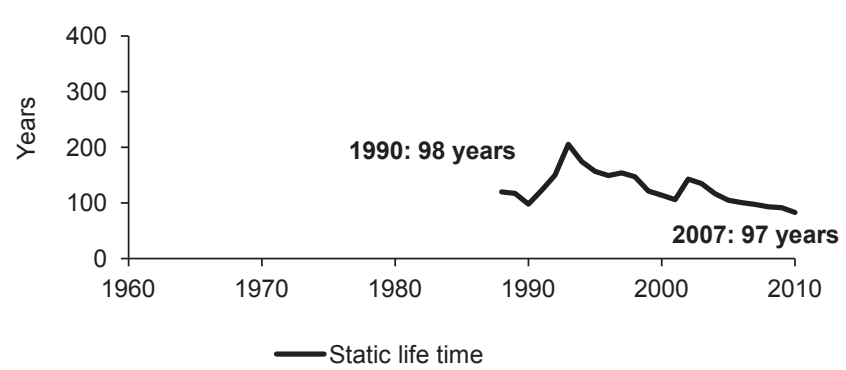

Refinery production
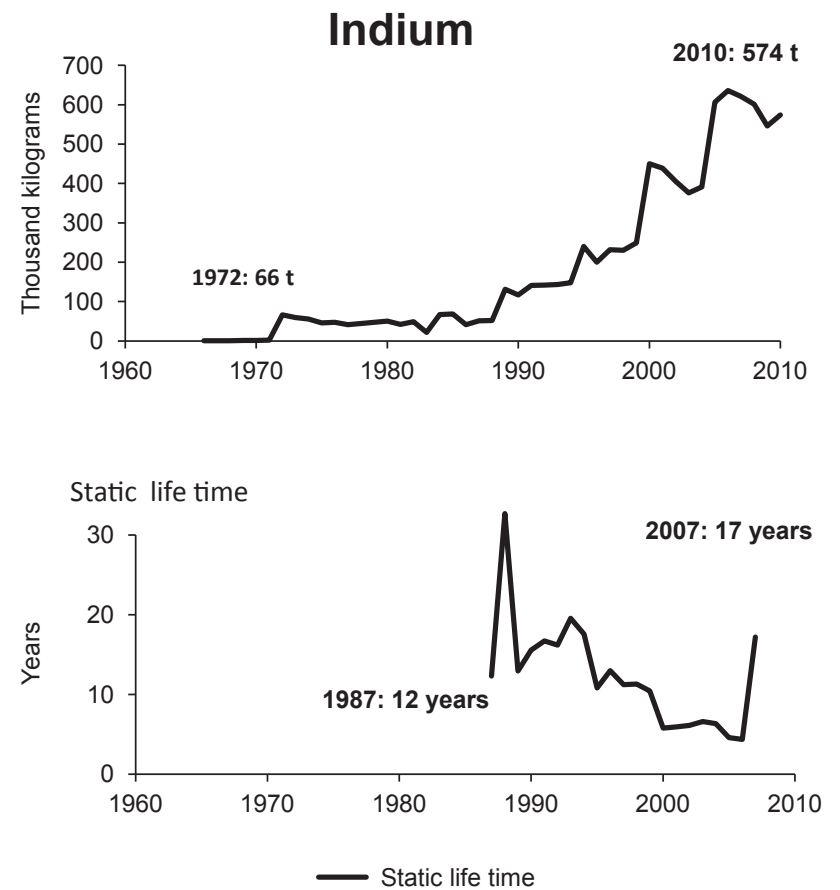